\title{
Skolyoz Hastaları İçin Omurga Ağrılarını Hafifleten Karbon Filmli Korse Tasarımı
}

\author{
Mehmet Erhan Şahin ${ }^{1 *}$ \\ 1* Isparta Uygulamalı Bilimler Üniversitesi, Teknik Bilimler Meslek Yüksekokulu, Biyomedikal Cihaz Teknolojisi Bölümü, Isparta, Türkiye, (ORCID: 0000-0003- \\ 1613-7493), erhansahin@isparta.edu.tr
}

(İlk Geliş Tarihi Aralık 2020 ve Kabul Tarihi Ocak 2021)

(DOI: $10.31590 /$ ejosat.849840)

ATIF/REFERENCE: Şahin, M.E., (2021). Skolyoz Hastaları İçin Omurga Ağrılarını Hafifleten Karbon Filmli Korse Tasarım. Avrupa Bilim ve Teknoloji Dergisi, (22), 416-420.

$\ddot{\mathbf{O z}}$

Skolyoz, nedeni tam olarak bilinmeyen omurganın ve omurlar arasında meydana gelen deformasyondur. Normal bir insan omurgasında omurlar bel sirt ve boyun bölgelerinde düz bir şekilde uzanırken skolyoz durumunda sola ya da sağa doğru yer değiştirmiş durumdadırlar. Skolyoz hastalığının tedavisi; fizik tedavi ile egzersiz, cerrahi operasyon ile omurgaya müdehale ve korse kullanı ile yapılmaktadır. Korse tedavisinde, korsenin gün içinde uzun süre kullanımından dolayı korse tedavisi gören hastaların birçoğu omurga çevresinde oluşan ağrılardan şikayet etmektedir. Bu çalışmada uzun süre skolyoz korsesi kullanımına bağlı oluşan ağrıları en aza indirmek amaçlanmıştır. İlk olarak kişiye özel korse tasarımı gerçekleştirilmiştir. Bu tasarım için 3 boyutlu tarayıcılar ve cad-cam yöntemleri kullanılmıştır. Fizik tedavide sıcak ve soğuk uygulamaları çeşitli hastalıkların tedavisinde kullanılmaktadır. Üretilen skolyoz korsesinin omurga hizasına karbon film yerleştirilerek bu bölgenin ısınması sağlanmıştır. Ayrıca buraya eklenen mikroişlemci kontrollü elektronik bir devre yardımıyla fizik tedavi koşullarına uyum sağlayacak şekilde sıcaklık değerleri kontrolü sağlanmıştır. Bu sayede bölgeden geçen damarların genişlemesi, kan dolaşımının hızlanması ve ağrının hafiflemesi amaçlanmıştır.

\section{Corset Design Using Carbon Film For Scoliosis Patients To Relieve Spine Pain}

\begin{abstract}
Scoliosis is the deformation that occurs between the spine and vertebrae of unknown cause. In a normal human spine, the vertebrae lie flat in the lower back and neck regions, while in the case of scoliosis, they are displaced to the left or right. Treatment of scoliosis disease; Physical therapy, exercise, surgical operation, intervention to the spine and using a corset. In corset treatment, most of the patients who receive corset treatment due to the long use of the corset during the day complain of pain around the spine. In this study, it was aimed to minimize the pain caused by the use of scoliosis brace for a long time. First, a personalized corset was designed. 3D scanners and cad-cam methods were used for this design. Hot and cold applications in physical therapy are used in the treatment of various diseases. Carbon film was placed at the spine level of the produced scoliosis corset and this area was warmed. In addition, with the help of a microprocessor controlled electronic circuit added here, temperature values are controlled in accordance with physical therapy conditions. In this way, it is aimed to expand the vessels passing through the region, accelerate blood circulation and relieve pain.
\end{abstract}

Keywords: Scoliosis, Biomedical, Corset design

\footnotetext{
*Sorumlu Yazar: erhan.sahin@isparta.edu.tr
} 


\section{Giriş}

Eğrilik anlamına gelen skolyoz ilk olarak Hipokrat tarafindan tarihte ilk defa "Corpus Hippocraticum" kitabında ortaya konmuştur (Weinstein ve Buckwalter, 2005). Sağlıklı bir bireyde vertebral kolon sagittal düzlem üzerinde fizyolojik eğriliklere sahipken; vertebralar koronal ve transvers düzlemlerde nötral pozisyonda yer alırlar. Koronal planda aynı çizgi üzerinde dizilmesi gereken vertebral kolonda herhangi bir nedenle bu dizilimin bozulmasına ve bir eğriliğin ortaya çıkmasına skolyoz denir (Şekil 1). Bir başka ifadeyle ayakta çekilen röntgen filimlerinde hesaplanan omurgalar arası Cobb açısı ile ölçülen $10^{\circ}$ ve üzerindeki lateral eğrilikler skolyoz olarak tanımlanır (Korkmaz ve ark., 2015). Skolyoz yalnızca koronal plan üzerindeki bozulmalarla sınırlı kalmayıp sagittal ve aksiyel planları da içine alan 3 boyutlu bir deformiteyi oluşturur. Skolyoz, fiziki görüntü, sırt ağrısı gibi sorunların yanında akciğer kalp fonksiyon bozukluklarına neden olarak solunum sıkıntıları yaşanmasına neden olabilir (Lenhert-Schroth, 2007, Solberg, 2008).
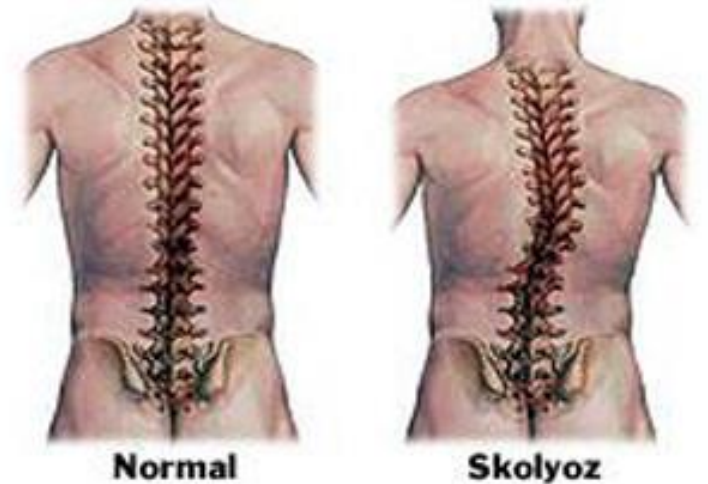

Şekil 1. Normal ve skolyoz omurga görünümü

Skolyoz oluşumunun birçok nedeni olabilir. Bunlar; çevresel faktörler, genetik faktörler, romatizmal hastalıklar, tümörler, nöromüsküler ve idiyopatik (nedeni bilinmeyen) nedenlerdir (Skaggs ve ark., 2014). Çevresel faktörler, duruş pozisyonunun yanlış olması uzun süre bilgisayar kullanımı ve ağır yük taşınmasından kaynaklanabilir (Fadzan ve BettanySaltikov, 2017). Genetik faktörler, doğuştan olabilir. Nöromüsküler nedenler, yumuşak dokularda oluşan bozukluklardan kaynaklanmaktadır. Kas veya kemik dokularda da meydana gelen zedelenmeler sonucunda da ortaya çıkabilmektedir (Weiss ve ark., 2016). İdiyopatik skolyoz nedeni tam olarak bilinmeyen bir tip skolyozdur Skolyoz hastalarının $\% \quad 80-\% \quad 90$ 'ında teşhis edilen en s1k görülen idiopatik skolyozdur (Lonstein, 1994).

Skolyoz, omuz seviyesi fark ölçümü ve eğilme testleri ile fiziksel muayene ile tespit edilebilir. Göz ile bakıldığında, vücut ile kollar arasındaki mesafenin farklı olduğu, omuz seviyesi ve kalçalar eşitsizlik, kürek kemiğinde tümsek ve göğüs kafesinde asimetri gözlenebilir. (Otman, 1998). Skolyozun kesin tan1 yöntemi Şekil 2' de örnek olarak gösterildiği gibi tüm omurgayı kapsayan radyolojik röntgen görüntüleridir. Ayakta çekilen bu görüntüler ile omurganın eğrilik derecesi belirlenir. Omurga da eğriliğin başladığı ve bittiği omurlar arası açı derecesine bakılır. $\mathrm{Bu}$ açıya Cobb açısı denir. Radyolojik röntgen görüntülerinden e-ISSN: 2148-2683 omurganın laterale olan 10 derece üzerindeki eğrilikler skolyoz olarak değerlendirilir (Karachalios ve ark., 1999, Greiner, 2016). Omurganın esnekliğini test etmek için bazı durumlarda magnetikrezonans (MR) görüntüleri gerekli olabilir.

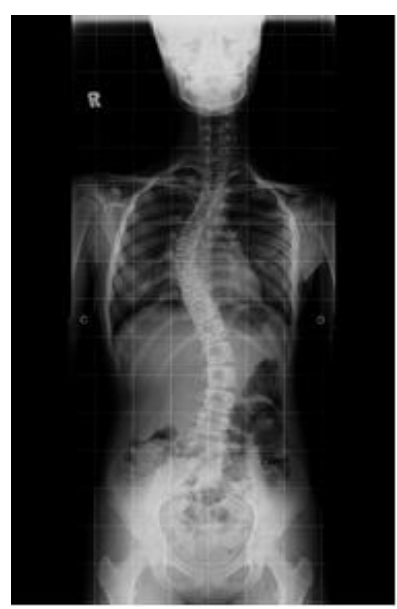

Şekil 2. Örnek bir röntgen görüntüsü

Skolyoz hastalığının tedavisi, hastalığın çeşidine göre farklılık gösterir. Genellikle ilaç, egzersiz, fizik tedavi, korse kullanımı gibi tedavi yöntemleri uygulanmaktadır. Cerrahi tedavi ise en son tercih edilen yöntemdir. Fizik tedavi ile tedavide hasta belirli egzersiz hareketlerini yapması sağlanır. Yeni başlangıç ya da ilerlememiş vakalarda korse kullanımı uygulanır. Korse kullanımı hastalığın ilerlememesi ve cerrahi operasyona gerek kalmaması için önemlidir. Tedavi için kullanılan çeşitli korse tipleri vardır. Bunlar; Thoraco-Lumbo-Sacral Orthosis (TLSO) korsesi, kol altı korsesi olarak da adlandırılır, vücuda tam olarak oturacak şekilde kişiye özel üretilir. Cervico-Thoraco-LumboSacral Orthosis (CTLSO) korsesi, sırt bölgesi eğriliklerinde kullanılır. Charleston Bending korsesi, eğriliğin tersi yönde yön verilerek daha fazla düzeltici kuvvet uygulanır gece korsesi olarak da adlandırılır. SpinerCor; dinamik bir korse olup omurga hareketine izin verir, hastaya özel üretilir. Korse tedavi yönteminde olumlu sonuçlar alabilmek için bazı şartlar gereklidir. Buradaki en önemli husus korsenin vücut yapısına uygun olmasıdır. Ayrıca hasta egzersizlerini düzenli olarak yerine getirmelidir ve günde $20-23$ saat korse kullanmalıdır. $\% 20$ ve $\% 40$ derece olan eğriliklerde, çocuklarının ergenlik dönemine girmeden önceki dönemlerde kullanılması etkili sonuçlar vermektedir. (Matsumoto ve ark., 2013, Weiss ve ark., 2003).

Fizik tedavide egzersiz, elektrik akımı, ışın ve 1sı gibi birçok tedavi yöntemi kullanılmaktadır. Bunlardan sıcak ve soğuk uygulamalar sıklıkla kullanılan tedavi yöntemleridir. 1920'li yıllarda derin dokuların 1sıtılmasını hedefleyen çalışmalar yapılmış ve günümüzdede kullanılmaktadır (Altun ve ark., 2015). Sicak uygulama ile yapılan tedavi (Termoterapi) de uygulanan bölgedeki kaslarda gevşeme olur. Kasların gevşemesi ile burada bulunan kan damarları genişler, kan dolaşımı hızlanır ve dokulara bol oksijen taşınır. Böylelikle burada bulunan dokularda rahatlama ve hücrelerde yenilenme sağlanır. Aynı zamanda sıcak uygulamanın sinir dokusu üzerine etkileri üzerinede çalışmalar yapılmakta ve sinir uyarılma eşiğinin düştüğü, sinir ileti hılarını arttığı gözlenmenmiştir (Oğuz, 2004). 
Bu çalışmada gün içinde 20-23 saatleri bulun uzun süre korse kullanan skolyoz hastalarının omurgalarında oluşan ağrıları hafifletmek amaçlanmıştır. Bu amaçla vücut ölçülerine uygun olarak korse tasarımı gerçekleştirilmiştir. Uzun kullanıma bağlı ağrıyı gidermek için fizik tedavide de kullanılan bölgesel 1S1 uygulaması omurga hizasına yerleştirilen karbon film ve otomatik kontrollü bir sistem tasarlanmıştır. Bu sayede buradaki ağrı noktarında kan dolaşımı hızlandırılarak ağrıyı hafifletme hedeflenmiştir.

\section{Materyal ve Metot}

\subsection{Cad-Cam ile Korse Tasarımı}

Skolyoz korse yapımında hastanın vücut ölçüsünü alabilmek için alçıdan kalıp çıkarılarak el ile düzeltme yapılmaktaydı. Şekil 3'de görüldüğü gibi ilerleyen teknoloji sayesinde lazer tarama yöntemi veya üç boyutlu kameralar ile hastanın üç boyutlu görüntüsü elde edilebilmektedir. $\mathrm{Bu}$ sayede hastanın alçı ile teması ortadan kalkmakta, ölçü alma işlemi süresi kısaltmakta, her açıdan mutlak bir standardizasyon sağlanmaktadır.

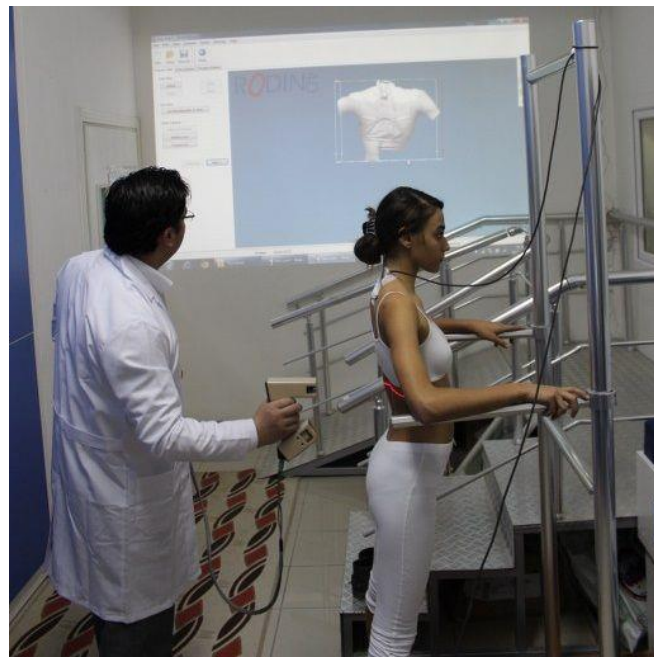

Şekil 3. 3D kamera ile tarama örnek görüntü

3 boyutlu vücut tarama için stereografik, yapısal 1 şı ve lazer tarama yöntemi gibi farklı yöntemler kullanılmaktadır. Bu tarama yöntemleri, kişi veya nesne sabit bir şekilde durduğu andaki görüntülerini kullanarak hızlı bir şekilde dijital olarak oluşturulmasını sağlamaktadır. Lazer tarama yönteminde, vücut üzerine bir lazer 1şık çizgisi oluşturmakta ve bu çizgi tarama için yer alan başlıklardaki kameralarla eşleştirilmektedir. (Yüksel ve Oktav Bulut, 2019).

Şekil 4' de görüldüğü üzere lazer tarama işlemi ile hastanın 3 boyutlu vücut görüntüsü dijital olarak bilgisayar ortamına aktarıldıktan sonra tarama görüntüsü ile hastanın röntgen filmi görüntüleri birleştirilerek 3 boyutlu model uzman kişi tarafindan düzeltmeler yapılarak tasarlanır.

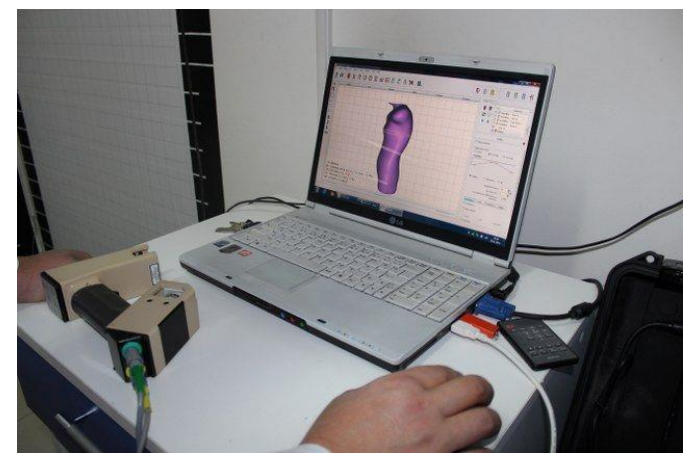

Şekil 4. 3D bilgisayar görüntüsü

Dijital olarak elde edilen 3 boyutlu görüntü robotik model işleme CNC makineleri tarafindan hassas bir şekilde üretilmektedir. (Şekil5). Son yıllarda teknoljik gelişmeler sayesinde korse üretimi 3D yazıcilar sayesinde de yapilabilmektedir.

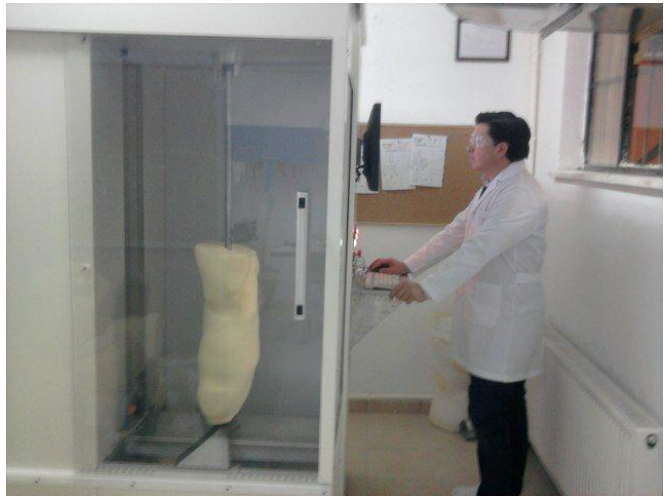

Şekil 5. Robotik model üretim görüntüsü

\subsection{Karbon Film}

Karbon filmler; tel ve rezistans kullanılmadan üretilen 1sıtıcılardır. İçerisindeki nano-karbon özel karışım ile ısıtma sağlanır. Şekil 6' da görüldüğü gibi ısı kaynağı ortalarda yer alan siyah renkli çok ince nano-karbon katmanlardır ve çok sayıda katmandan oluşur. Isıtıcı film $0,5 \mathrm{~mm}$ kalınlığındadır. Karbon film, çok kısa sürede 1sındığı için etrafi anında 1sıtmaya başlar. Isı, yüzeyde eşit olarak dağılır ve böylece tüm bölgenin kolayca 1sınması sağlanır. Karbon filmlerin elektrik beslemesi her iki tarafında bulunan gümüş iletkenler ile yapılır. Yalıtkan malzemeden üretildiğinden elektrik kaçağı oluşturmaz ve kişiye herhangi bir zarar vermez (Erden ve Yıldız, 2015).

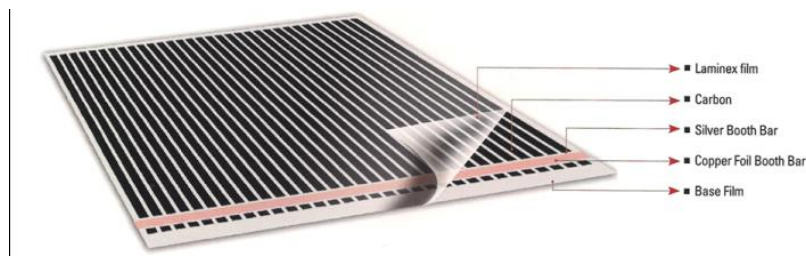

Şekil 6. Karbon film 


\section{Tasarlanan Skolyoz Korsesi}

Lazer tarama ve X-Ray görüntüleri kullanılarak elde edilen üç boyutlu görüntü ile elde edilen skolyoz korsenin omurga hizası boyunca karbon film yerleştirilmiştir. Karbon film ince bir yapıya sahip olduğundan tasarım ve kullanım açısından problem yaratmamaktadır. Karbon filmin sicaklık derecesini ayarlayabilmek için mikrodenetleyici kontrollü termostat devresi tasarlanmıştır. Geliştirilen korse Şekil 7'de gösterilmiştir.

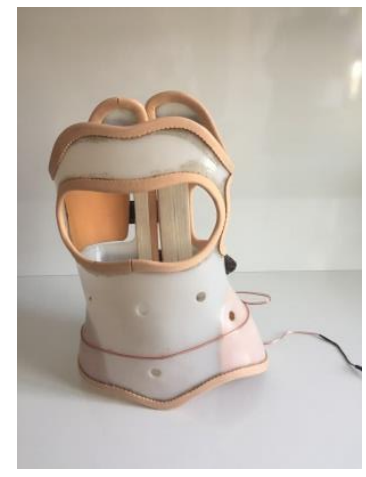

(a)

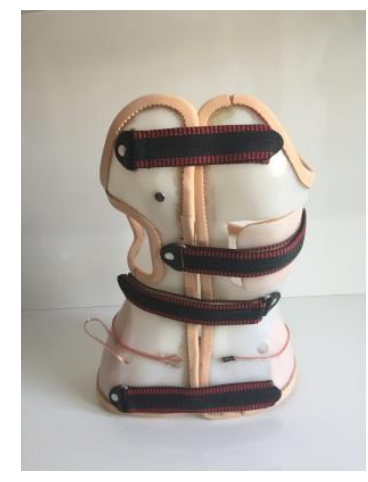

(b)

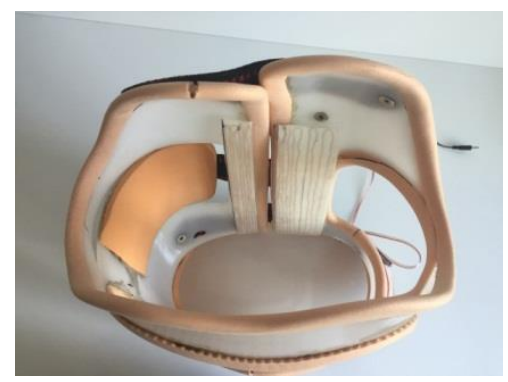

(c)

Şekil 7. Tasarlanan skolyoz korsesinin a) önden b) arkadan c) üstten görünüşü

İnsanın fizyolojik olarak vücut içi sıcaklığ $37 \pm 0,5^{\circ} \mathrm{C}$, deri yüzey sıcaklığı ise ortalama $32,5 \pm 0,5{ }^{\circ} \mathrm{C}$ arasındadır. Deri yüzeyindeki $1-3{ }^{\circ} \mathrm{C}$ 'lik sıcaklık değişimleri herhangi bir rahatsızlık vermemektedir. İnsan konfor sıcaklık derecesi $21-23$ ${ }^{\circ} \mathrm{C}$ arasinda ideal kabul edilmektedir (Öngel ve Mergen, 2009, Huang ve $\mathrm{Xu}, 2006$ ). Sicak fizik tedavi uygulamarında derin doku isısının $40-45.5^{\circ} \mathrm{C}$ aralığında tutulması ve 3-30 dakika süresinde uygulanması gerekmektedir (Yıldız ve ark., 2019).
Şekil 8' de olduğu gibi LM35 1S1 sensörü ve yer kaplamaması açısından Arduino nano kullanılarak karbon filmin sıcaklık derecesi $42{ }^{\circ} \mathrm{C}$ olacak şekilde ayarlanmıştır. 1 derece alt ve üst sicaklık seviyelerinde devreye girerek bu bölgenin sıcaklığını sabit tutmaktadır. Bu bölgenin fazla 1sıyıya maruz kalmasını önlemek için 15 dakika sonunda sistem kapanmakta ve bu istenilen zaman dilimlerinde programlanarak devreye girmesi sağlanmaktadır. İstenildiğinde de manuel olarak kullanılabilmektedir.

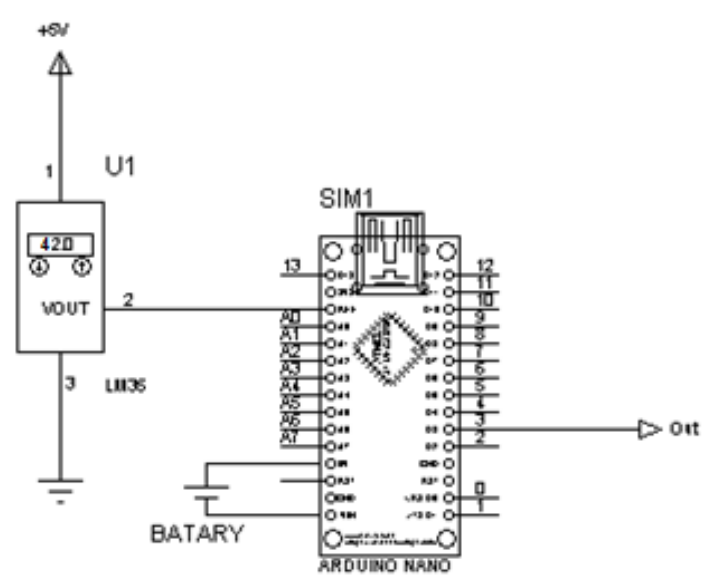

Şekil 8. Sicaklık kontrol devresi

\section{Sonuç}

Skolyoz omurganın sirt veya bel bölgelerinin yana doğru eğilmesidir. Skolyoz tanı ve teşhisi fiziksel muayene veya kesin olarak radyoljik görüntüler ile konulabilmektedir. 10 derecenin üstündeki omurga eğrilikleri skolyoz olarak tanımlanmaktadır. Skolyozun birkaç tedavi yöntemi vardır. Bunlardan bir taneside korse kullanımıdır. Çeşitli korse tipleri olmasına rağmen uzun süre kullanım gerekmektedir. Buda omurgada ağrıya sebep olabilmektedir.

Tasarlanan korse üç skolyoz hastasının kullanımına sunulmuştur. Karbon filmli skolyoz korsesi ile her iki kenarında gümüş veya bakır iletkenler bulunan ve elektrik bağlantısı buradan sağlanan nano karbon özellikli filmin, skolyoz korsesinin omurga hizası boyunca yerleştirilerek bu bölgenin fizik tedavi koşullarına uygun bir şekilde isıtılması ve bu bölgeden geçen kan damarların genişlemesi sağlanmıştır. Isı artışyla oluşan vazodilatasyon (damarların genişletilmesi) etkisiyle kan dolaşımı hızlanmış, dokuların beslenmesi sağlanmış ve dolayısıyla ağrı hissinde belirgin azalmalar görülmüştür. Kısacası skolyoz da korse tedavisi uygulanan hastanın omurga çevresinin 1sıtılması ile ağrının en aza indirilmesi ve konforu sağlanmıştır.

\section{Kaynakça}

Altun, H., Özer, M., Akseki, D., (2015). Sporda Propriosepsiyon ve Sicak - Soğuk Uygulamalarla İlişkisi, CBÜ Beden Eğitimi ve Spor Bilimleri Dergisi, 10 (1), 10-35.

Erden, S., Yildız H., (2015). Karbon/Poliamid 12 Film Kompozit Üretimi, Tekstil ve Mühendis, 22: 100,32-37. http://dx.doi.org/10.7216/1300759920152210004 
Fadzan, M., \& Bettany-Saltikov, J., (2017). Etiological Theories of Adolescent Idiopathic Scoliosis: Past and Present, The Open Orthopaedics Journal, 11 (Suppl-9), 1466-1489.

Greiner, K., American Family Physician., (2016). Adolescent Idiopathic Scoliosis: Radiologic Decision-Making, http://www.aafp.org/afp/2002/0501/afp20020501p1817f2.gif

Huang, J, Xu, W., (2006). A New Practical Unit for theAssessment of the Heat Exchange of Human Bodywith the Environment, Journal of Thermal Biology, 31: 318.322.

Karachalios, T., Sofianos. J., Roidis, N., Sapkas, G., Korres, D., and Nikolopoulos, K., (1999). Ten-Year Follow-Up Evaluation of a School Screening Program for Scoliosis, Spine, 24- 22, 2318-2324.

Korkmaz, M.F., Sevimli, R., Selcuk, E.B., Cigremis, Y., (2015). Üç Boyutlu Omurga Deformitesi: Skolyoz, Medicine Science, 1796-808, doi: 10.5455/medscience.2014.03.8177.

Lonstein, D., (1994). Adolescent idiopathic scoliosis. Lancet, 1994;344(8934):1407-12. doi: 10.1016/s01406736(94)90572-x, PubMed: 7968079.

Lenhert-Schroth, C. ,(2007). The Schroth scoliosis three dimensional treatment. Norderstedt: Books on Demand $\mathrm{GmbH}$.

Matsumoto, M., Watanabe, K., Hosogane, N., Toyama, Y., (2013). Updates on surgical treatments for pediatric scoliosis, The Japanese Orthopaedic Association, 19:6-14.

Oğuz, H. (2004). Tedavide sıcak ve soğuk, Tibbi Rehabilitasyon. s. 333-353, 2. Bask1 Cilt-1, İstanbul: Nobel Tip Kitabevleri,

Otman, A., S., Demirel H., Sade, A., (1998) Tedavi Hareketlerinde Temel Değerlendirme Prensipleri. 2. Baskı. Hacettepe Üniversitesi Fizik Tedavi ve Rehabilitasyon Yüksekokulu Yayınları.

Öngel, K., Mergen, H., (2009). Is1l Konfor parametrelerinin insan vücudundaki etkilerine yönelik literatür taraması, S.D.Ü. Tıp Fakültesi Dergisi 2009:16(1)/ 21-25.

Skaggs, D.L., Akbarnia, B.A., Flynn, J.M., Myung, K.S., Sponseller, P.D., Vitale, M.G., (2014). Classification of Growth Friendly Spine Implants, J Pediatr Orthop., Volume 34 , p 260- 274.

Solberg, G., (2008). Postural disorders \& Musculoskeletal Dysfunction Diagnosis Prevention and Treatment, Sydney: Churchill Livingston.

Yıldı,, M., Gunt, A., Er, P., Gürler, V , Naneci, M . (2019). Termoelektrik Modül Kullanılarak Gerçekleştirilen Bilgisayar Tabanlı Fizik Tedavi Cihazı, Düzce Üniversitesi Bilim ve Teknoloji Dergisi, 7 (1), 689-698. doi: 10.29130/dubited.466488

Yüksel,H., Oktav Bulut, M. (2019). Üç Boyutlu Tarama Sistemleri, Tekstil ve Mühendis, 26: 116, 406-414. https://doi.org/10.7216/1300759920192611612

Weinstein, S.L., Buckwalter, J.A., (2005). Turek's Orthopaedics Principles and Their Application. 6th edition, Philadelphia: Lippincott Williams \& Wilkins, 482- 92.

Weiss, H.R., Weiss, G., \& Petermann, F., (2003). Incidence of curvature progression in idiopathic scoliosis patients treated with scoliosis in-patient rehabilitation (SIR): an age-and sex-matched controlled study, Pediatric Rehabilitation, 6(1), 23-30.

Weiss, H.R., Turnbull, D., Tournavitis, N., Borysov, M., (2016). Treatment of ScoliosisEvidence and Management (Review of the Literature), Middle East J Rehabil Health. 2016 April; 3(2): e35377. 